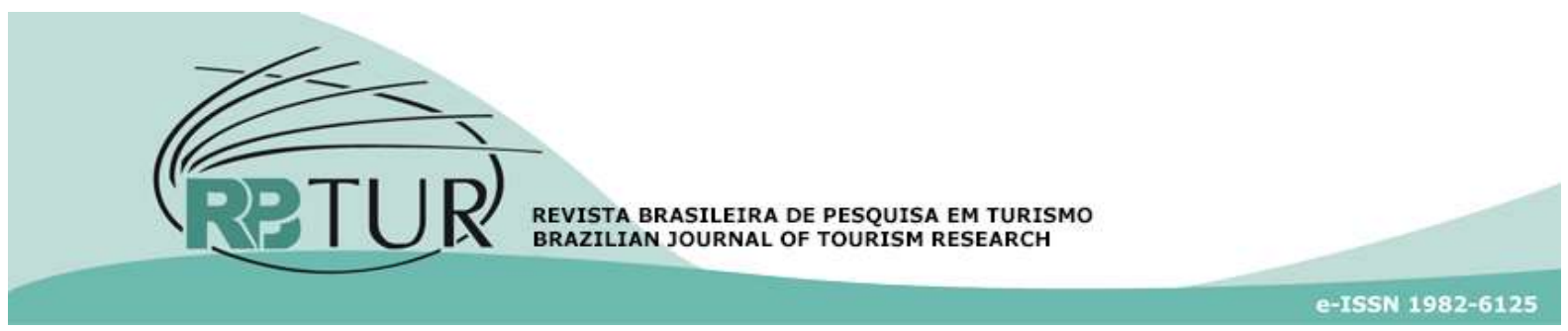

Artigo

DOI: http://dx.doi.org/10.7784/rbtur.v12i2.1399

\title{
A hospitalidade na rede social Couchsurfing: Cruzando a soleira virtual em Jaguarão, no extremo Sul do Brasil
}

\author{
The hospitality in the social network Couchsurfing: Crossing the \\ virtual threshold in Jaguarão, in the extreme south of Brazil
}

\section{La hospitalidad en la red social Couchsurfing: Cruzando el límite virtual en Jaguarão, en el extremo sur de Brasil}

\author{
Marcina Amália Nunes Moreira ${ }^{1}$ \\ Christianne Luce Gomes ${ }^{2}$
}

Resumo: Este artigo aborda uma prática social mediada por uma rede social virtual de viajantes denominada Couchsurfing. Traduzida como "surfe de sofá", essa prática é conhecida pela oferta gratuita de hospedagem, mundialmente, viabilizando a interação online e offline entre os sujeitos cadastrados, além de promover o câmbio de hospitalidade, em que anfitrião vira hóspede em outras situações de viagem e vice-versa. Nesta pesquisa, foram investigados os anfitriões e hóspedes do município de Jaguarão, localizado no extremo sul do estado do Rio Grande do Sul (RS), Brasil. Os objetivos do artigo são identificar e discutir os principais interesses e motivações pela rede e pelas viagens Couchsurfing, entre os anfitriões e hóspedes jaguarenses, bem como compreender o sistema de trocas entre hóspedes e anfitriões tendo como inspiração os estudos da hospitalidade baseados na Teoria da Dádiva, de Marcel Mauss. A investigação teve abordagem qualitativa e aproximou-se do método netnográfico. O percurso metodológico contou com estudo bibliográfico e pesquisa de campo ciberespacial, com entrevistas semiestruturadas e observações. As trocas se dão de maneira online e offline, em diferentes prismas. A pesquisa apresenta novos desafios para os estudos do turismo, lazer e hospitalidade no contexto de práticas sociais emergentes, como o Couchsurfing.

Palavras-chave: Hospitalidade. Turismo. Rede social virtual. Lazer. Couchsurfing.

\footnotetext{
${ }^{1}$ Universidade Federal de Viçosa (UFV), Florestal, MG, Brasil. Concepção do problema de pesquisa, definição dos objetivos e da metodologia, estudo bibliográfico, realização de entrevistas, análise dos resultados e redação do artigo.

2 Universidade Federal de Minas Gerais (UFMG), Belo Horizonte, MG, Brasil. Definição dos objetivos e da metodologia da pesquisa, análise dos resultados, estruturação do texto e redação do artigo.
}

Artigo recebido em: 18/12/2017. Artigo aceito em: 05/02/2018.

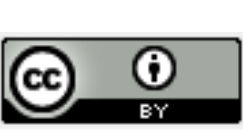




\begin{abstract}
This article addresses a social practice mediated by a virtual social network of travelers called Couchsurfing. Translated as "sofa surfing", this practice is known for the free hosting offer, worldwide, enabling online and offline interaction between registered individuals, as well as promoting the exchange of hospitality, in which host becomes a guest in other travel situations and vice versa. In this research, the hosts and guests of the municipality of Jaguarão, located in the extreme south of the state of Rio Grande do Sul (RS), Brazil, were investigated. The objectives of the article are to identify and discuss the main interests and motivations for the network and Couchsurfing trips among Jaguarian hosts and guests, as well as to understand the system of exchange between guests and hosts inspired by the studies of hospitality based on the Theory of Gift, by Marcel Mauss. The research had a qualitative approach and approached the etnographic method. The methodological course included a bibliographical study and a cyberspace field research, with semi-structured interviews and observations. The exchanges take place online and offline, in different prisms. The research presents new challenges for tourism, leisure and hospitality studies in the context of emerging social practices, such as Couchsurfing.
\end{abstract}

Keywords: Hospitality. Tourism. Virtual social network. Recreation. Couchsurfing.

Resumen: Este artículo aborda una práctica social mediada por una red social virtual de viajeros denominada Couchsurfing. En el caso de que se trate de un "surfe de sofá", esta práctica es conocida por la oferta gratuita de hospedaje, mundialmente, viabilizando la interacción online y offline entre los sujetos registrados, además de promover el cambio de hospitalidad, en que anfitrión se convierte en huésped en otras situaciones de viaje y viceversa. En esta investigación, fueron investigados los anfitriones y huéspedes del municipio de Jaguarão, ubicado en el extremo sur del estado de Rio Grande do Sul (RS), Brasil. Los objetivos del artículo son identificar y discutir los principales intereses y motivaciones por la red y por los viajes Couchsurfing entre los anfitriones y huéspedes jaguarenses, asi como comprender el sistema de intercambios entre huéspedes y anfitriones teniendo como inspiración los estudios de la hospitalidad basados en la Teoría de la Dádiva de Marcel Mauss. La investigación tuvo un enfoque cualitativo y se acercó al método etnográfico virtual. El recorrido metodológico contó con estudio bibliográfico e investigación de campo ciberespacial, con entrevistas semiestructuradas y observaciones. Los intercambios se dan de manera online y offline, en diferentes prismas. La investigación presenta nuevos desafíos para los estudios del turismo, ocio y hospitalidad en el contexto de prácticas sociales emergentes, como el Couchsurfing.

Palabras clave: Hospitalidad. Turismo. Red social virtual. Ocio. Couchsurfing.

\section{INTRODUÇÃO}

O presente artigo é parte de uma pesquisa dedicada à hospitalidade mediada por uma rede social virtual de viajantes (RSV): Couchsurfing. Essa palavra, em inglês, tem o significado literal de "surfe de sofá" e faz referência a viagens com pernoites na "sala de estar" dos hosts (anfitriões), por parte dos guests (hóspedes). É uma rede de hospitalidade em que os seus membros (surfers), contextualizados enquanto anfitriões (hosts), podem abrigar durante alguns dias, livre e gratuitamente, outros guests.
O Couchsurfing foi idealizado pelo norte-americano Casey Fenton, aliado a outros fundadores da RSV, a partir de uma mensagem eletrônica enviada a estudantes da Islândia no contexto de um evento, solicitando hospedagem na residência dos mesmos, o que lhe proporcionaria conforto psicológico e fisiológico (Figueiredo, 2008). Como contrapartida, o idealizador do Couchsurfing ofereceu sua experiência cultural aos potenciais anfitriões islandeses. A busca de um meio de hospedagem alternativo, em domicílio, buscava evitar os padrões estabelecidos pelo mercado e 
agências de viagem, que eram as tradicionais intermediadoras de serviços de hospedagem, alimentação e entretenimento, entre outros.

A princípio, o Couchsurfing apresentava-se como uma RSV sem fins lucrativos que oferecia a vantagem de alojamento gratuito pelo mundo inteiro sem qualquer custo ou obrigação adicional. No entanto, segundo informações contidas na página virtual da rede, a partir de 2011 foi instituída uma taxa de pagamento anual no valor de 18 euros. Essa taxa é para arcar com os custos de validação do perfil de cada pessoa cadastrada, proporcionando mais segurança a cerca de 12 milhões de usuários da rede, distribuídos em mais de 200 mil cidades no mundo. Naquele mesmo ano, foi incorporada ao site a missão de "criar experiências de viagem baseadas na troca, na generosidade, na confiança interpessoal e no intercâmbio cultural." (http://www.couchsurfing.com/ab out/about-us/).

Alguns estudos sobre o Couchsurfing já foram realizados por pesquisadores de distintos países, sob diferentes lentes. A pesquisa de Bialski (2007) relacionou a prática do Couchsurfing ao "Turismo Íntimo", expressão que designa um sistema de troca no qual experiências de viagens e relacionamentos são compartilhados em diferentes espaços, como aqueles criados pelas redes on line, e não apenas nos espaços dominados pelo turismo tradicional. Outras publicações discutem a confiança interpessoal dos sujeitos cadastrados no Couch-surfing a partir de suas interações (Bialski \& Batorski, 2010; Shapiro, 2012; Cherney, 2014); assim como as barreiras ao uso do Couchsurfing considerando, em especial, a imagem do usuário com suas referências positivas e negativas (Bradbury, 2013; Liu, 2013; Yannopoulou, 2013). Zhu (2010), por sua vez, investigou membros cadastrados na RSV sem experiência de hospedagem na rede, seja como anfitrião ou como hóspede. Os resultados da pesquisa de Ronzhyn (2015) enfatizaram a conexão entre a confiança e a experiência no Couchsurfing, em que usuários mais experientes são os mais confiáveis.

O Couchsurfing também foi objeto de alguns estudos acadêmicos realizados no Brasil. Figueiredo (2008) buscou compreender as visões de mundo esboçadas a partir do sistema de trocas entre hóspedes e anfitriões, o que resultou em reflexões acerca da dádiva, da tolerância e do imaginário das viagens. Pode ser citado, ainda, um estudo no qual foi levantado, quantitativa e qualitativamente, o perfil dos usuários do Couchsurfing (Dutra, 2010). Os resultados indicaram que o perfil predominante é constituído por jovens com idade média de 28,5 anos, que dominam cerca de 3,87 idiomas. O conhecimento desses estudos, assim como a experiência como guest do Couchsurfing em Jaguarão, no Rio Grande do Sul, despertou o interesse pela realização da pesquisa que gerou este artigo.

Conforme apontado na Figura 1, o município escolhido como referência para a pesquisa localiza-se na microrregião Jaguarão e está a $395 \mathrm{~km}$ de Porto Alegre. No Brasil, faz limites com os municípios de Arroio Grande e Herval e, no Uruguai, com Rio Branco e Lago Merín (Cunha, 2012). 
Figura 1 - Localização de Jaguarão/RS

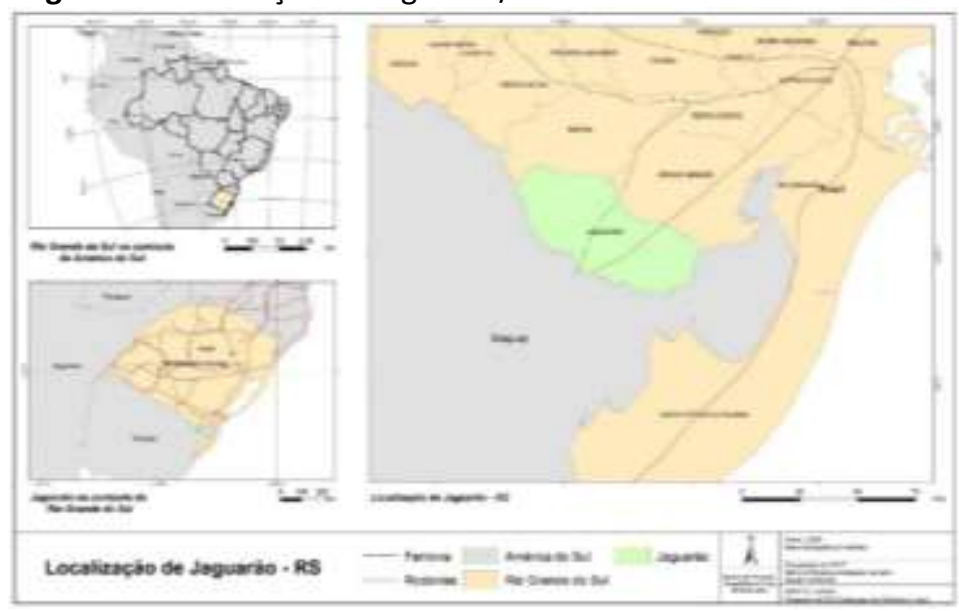

Fonte: IBGE (2017).

Organização: Elaborado pelas autoras

De acordo com o IBGE (2017) a cidade possui, em média, 28.230 habitantes, ocupando cerca de 2.051,021 $\mathrm{Km}^{2}$ e sua economia gira em torno da agropecuária e de serviços. No entanto, a partir da inauguração dos free-shops em Río Branco, no ano de 2003, constatou-se um crescente fluxo de turistas para a cidade uruguaia, despontando Jaguarão como "cidade dormitório". Algumas características conferem a Jaguarão uma sutileza em sua própria formação histórica, social e cultural, possivelmente direcionada para rememorar o tempo em que o Brasil e seus vizinhos lutavam por conquista territorial. Seu conjunto histórico e paisagístico foi tombado pelo Instituto do Patrimônio Histórico e Artístico Nacional, IPHAN, no ano de 2010. Segundo Ribeiro e Melo (2011) "trata-se do maior tombamento em número de exemplares de imóveis do Estado do Rio Grande do Sul, com mais de $800 "$.

Soma-se, a isso, o fato de Jaguarão ter despontado como uma cidade universitária desde 2008, quando foi ali instalado um campus da Universidade Federal do Pampa.
Isso fez com que muitos estudantes aprovados no Exame Nacional do Ensino Médio, ENEM, se deslocassem temporariamente para Jaguarão, tornando-se residentes no município ao longo da graduação. É importante ressaltar que Jaguarão possui vários restaurantes que tendem a valorizar a gastronomia local (o churrasco), além de contar com cerca de 20 meios de hospedagem, entre hotéis e pousadas (Prefeitura de Jaguarão, 2017). Paralelamente a esses meios de hospedagem, é comum o Couchsurfing ocorrer ali, o que remete às trocas interresidenciais de "sofá" no contexto doméstico. As relações sociais e a forma como os sujeitos interagem uns com os outros, na perspectiva da hospitalidade mediada por novas tecnologias, são merecedoras de atenção, segundo Lashley \& Morrison (2006).

A concepção de hospitalidade é central na pesquisa, apresentando-se como uma temática constante em torno das práticas de turismo, como salienta Panosso Neto (2013). Alguns autores, como Camargo (2004), fundamentam seus estudos e 
pesquisas na abordagem francesa da hospitalidade, na qual a "teoria da dádiva" formulada por Marcel Mauss (1974), é uma referência fundamental. Para o antropólogo francês, a expressão "dar, receber e retribuir" é uma relação que simboliza a troca. Ao oferecer um mimo ou um presente a alguém, o próprio gesto força quem o recebe a retribui-lo. Para o autor, as retribuições existem, ainda que de forma indireta. Desse modo, a dádiva justifica a cordialidade, as relações e as interlocuções humanas em cada sociedade. Perrot (2011) também trata a hospitalidade como dádiva e busca compreender as conexões e trocas estabelecidas entre quem hospeda e quem é hospedado.

Camargo (2006) considera a atividade turística como a superposição de dois sistemas de troca e evidencia a virtude do dom que subsiste no âmbito comercial: um deles é regido pelo contrato, por aquilo que está combinado entre as partes, e o outro é regido pelo dom, ou seja, por aquilo que não está formalmente pactuado, sendo portanto algo de difícil alcance pela simples observação. Para o autor, hospitalidade significa o ato de acolher o outro em todas as suas dimensões: abrigando, propiciando-lhe segurança, alimentando-o, entretendo-o no período de permanência em determinado local (Camargo, 2011). Godbout (1999), por sua vez, designa a hospitalidade como a "dádiva do espaço", espaço esse que concebe e proporciona a sociabilidade.

Esses fundamentos são relevantes para se compreender as práticas sociais imbricadas no fenômeno da hospitalidade, tais como o Couchsurfing no extremo sul do
Brasil - sejam elas concretizadas presencialmente ou mediadas pela plataforma virtual, à distância. Nessa perspectiva, os objetivos deste artigo são identificar e discutir os principais interesses e motivações pela rede e pelas viagens Couchsurfing, entre os anfitriões e hóspedes jaguarenses, bem como compreender o sistema de trocas entre hóspedes e anfitriões tendo como inspiração os estudos da hospitalidade baseados na Teoria da Dádiva, de Marcel Mauss.

\section{ESCOLHAS METODOLÓGICAS}

De abordagem qualitativa, esta pesquisa contemplou um conjunto de práticas interpretativas (Maingueneau, 2000) e preocupou-se, essencialmente, em compreender a hospitalidade a partir das práticas sociais mediadas por uma RSV mundial de viajantes em Jaguarão/RS. Para isso, foi realizado um estudo bibliográfico e uma "pesquisa de campo ciberespacial", baseada na netnografia, que, segundo Kozinets (2014), é uma abordagem etnográfica para mídias digitais.

A chegada da Internet colocou um desafio significante para a compreensão dos métodos de pesquisa. Através das ciências sociais e humanidades as pessoas se encontraram querendo explorar as novas formações sociais que surgem quando as pessoas se comunicam e se organizam via email, websites, telefones móveis e o resto das, cada vez mais, mediadas formas de comunicação. Interações mediadas chegaram à dianteira como chave, na qual, as práticas sociais são definidas e experimentadas. (Hine, 2005, p.1). 
A escolha pela netnografia conduziu a imersão no campo da pesquisa, que, após o cadastro prévio na rede Couchsurfing, possibilitou a observação virtual com instrumentalização de busca da própria rede.

[...] observar uma lista de discussão na internet ou uma comunidade virtual em um site de rede social trará dados materialmente distintos (como textos escritos, emoticons, imagens e links publicados pelos usuários, por exemplo) daqueles coletados em encontros presenciais. Para alguns, tal diferença justifica o emprego de termos como "etnografia virtual" e/ou "netnografia", ressaltando a diferença da "pura" etnografia. (Polivanov, 2013, p.6-7)

A princípio, o desafio foi identificar todos os sujeitos com perfil cadastrado, com domicílio ou que já haviam pernoitado com anfitriões em Jaguarão/RS, chegando-se a 40 surfers. A partir de então, navegou-se por entre as identidades desses sujeitos para conhecê-los, interpretar suas imagens e estilos, códigos, apegos e desgostos. Essa observação virtual, caracterizada como uma "errância on", foi o primeiro contato com os sujeitos envolvidos na RSV Couchsurfing no município em destaque.

Em seguida, foi feito contato individual com cada surfer selecionado, através de comunicação assíncrona (mensagem ou email), convidando-os para participar da pesquisa como voluntários. O retorno positivo foi dado por 13 surfers da rede social: 8 anfitriões e 5 hóspedes, para os quais foi enviado o Termo de Consentimento Livre e Esclarecido (TCLE) aprovado pelo Comitê de Ética em Pesquisa da Universidade Federal de Minas Gerais, bem como um roteiro prévio de uma entrevista a ser realizada posteri- ormente, seja in loco ou com o auxílio de ferramentas virtuais. Cada voluntário se autonomeou para que seu anonimato pudesse ser preservado: os anfitriões são Storck, Bird, Guru, Carlito, Fafá, Bee, Minervina e Leo; e os hóspedes são Potosí, Teo, Pucek, Flavnav e Bitmary.

Essa amostragem não probabilística foi "determinada por tipicidade e conveniência" (Laville \& Dionne, 1999, p.170), considerando-se os sujeitos prontamente disponíveis e acessíveis à participação voluntária na pesquisa, no período indicado. As entrevistas via skype contaram com o apoio do software Pamela, que gravou e salvou todo o roteiro visual e falado, possibilitando futura transcrição.

A análise interpretativa levou em conta a visão, princípios e políticas constantes na RSV Couchsurfing e foi corroborada por estudos da hospitalidade, em especial aqueles baseados na Teoria da Dádiva, de Marcel Mauss (1950, 1974). Essa teoria assumiu um importante papel enquanto recurso de apoio à compreensão da forma como aconteciam as trocas e as possibilidades de manutenção dos vínculos sociais desde as interações em rede até o interior das residências, metaforizadas pelo "sofá". Foi utilizada, portanto, para aclarar o tratamento dos dados coletados por meio de entrevistas, tendo como premissa que, segundo Godelier (1996, p.7), “o dom existe em todo lugar, embora não seja o mesmo em toda a parte".

O turismo, considerado como um amálgama em que subsistem as leis de defesa do consumidor através de cláusulas de contrato é, também, regido segundo as 
leis ancestrais do dom (Camargo, 2006). Diante dessa premissa, outras observações, que remetem diretamente aos objetivos da pesquisa, baseadas nos principais resultados de pesquisas anteriores, também foram incluídas na análise interpretativa dos dados coletados, conforme será tratado a seguir.

\subsection{Dinâmica e horizonte das RSV}

Segundo Luz (2012), com o individualismo crescente das últimas décadas, o ser humano se fragmenta. Porém, simultaneamente, como um ser social, tem necessidade de vínculos, o que o leva a buscar no ato da viagem alguns elos sociais íntimos e significativos. Trata-se de um paradoxo da "pós-modernidade": a liberdade cria o individualismo, mas, traz consigo a solidão e a carência afetiva, que são remediadas pela reintegração.

Bauman (2003) salienta que, embora as comunidades estejam cada vez mais efêmeras, ocasionais, a valorização do outro e o estreitamento de laços sociais se tornam necessários. $\mathrm{O}$ autor adverte:

Se vier a existir uma comunidade no mundo dos indivíduos, só poderá ser (e precisa sê-lo) uma comunidade tecida em conjunto a partir do compartilhamento e do cuidado mútuo; uma comunidade de interesse e de responsabilidade em relação aos direitos iguais de sermos humanos $\mathrm{e}$ igual capacidade de agirmos em defesa desses direitos. (Bauman, 2003, p.134)

Alguns dos agentes tecnológicos que permitiram a propagação desse comportamento social foi a internet e, no caso específico do turismo, o uso de redes sociais voltadas para os viajantes. Vila e Vila (2012) afirmam que a novidade não está no acesso à diversidade de informações disponibilizadas por meio da internet, mas na busca e nos modos de gestão dessas informações, tornando-as mais atrativas. Com a Web 2.0, passam a ser produzidos blogs, galerias de imagens, redes sociais e outras ferramentas.

De acordo com William \& Martell (2008), o turismo 2.0 utiliza plataformas em comum, que são inter-relacionadas com um sistema de redes. O conhecimento e sua circulação devem ser o motor dessa rede, que se auto organiza e se desenvolve pela retroalimentação sistêmica de seus próprios membros. Os sistemas turísticos não são, portanto, lineares. Portam-se de maneira complexa, dinâmica, incerta e imprevisível, sendo influenciados por elementos diretos da atividade turística, e indiretos e externos à rede, como as culturas, a política, os recursos sociais, naturais e humanos. Para manter seu bom funcionamento é demandada uma gestão diferenciada com monitoramento e aprendizagem social para sua adaptação em cenários mutáveis.

A orientação sistemática das redes trabalha as relações sociais por meio da estrutura horizontal, em que não há hierarquia social, uma vez que todos os usuários são consumidores e produtores de informações (Castells, 2003). Dessa forma, as informações circulam entre um número bem maior de pessoas, potencializando seu compartilhamento. Para que isso aconteça, segundo Alves (2011), as relações devem ser 
baseadas na confiança, que está atrelada ao conhecimento do indivíduo sobre determinado assunto. Quanto maior o conhecimento, maior a confiança. Caso contrário, a sociedade se desintegra.

Esse é o contexto que propicia a constituição de uma rede social virtual (RSV) como o Couchsurfing Project, que modificou significativamente, para seus usuários, o modo de buscar e vivenciar a hospedagem. $\mathrm{O}$ Couchsurfing é o deslocamento voluntário e temporário de pessoas ou grupos, por motivos de lazer ou outros, gerando relações interpessoais, sociais, econômicas e culturais. É uma prática contemporânea que busca experiências pessoais profundas ligadas à felicidade (Stern, 2009). Tal prática é viabilizada pelo acesso e cadastro junto ao site, e nessas condições o turista é visto como convidado, e não como forasteiro, na compreensão de Bialski (2007).

A RSV Couchsurfing incentiva que as pessoas acolham umas às outras em suas residências e se constituam ora como hóspedes, ora como anfitriões. Tecnicamente, por não existir um vínculo contratual e monetário que caracterize a contratação e a prestação de um serviço, os criadores da ideia do intercâmbio de hospitalidade organizaram uma regulamentação própria. O link "About us" ("sobre nós") existente no site explicita valores, princípios e políticas de uso do Couchsurfing:

Visão: Visamos a um mundo onde todos possam explorar e criar conexões significativas com pessoas e lugares, onde estiverem. Construir conexões

3 Informações divulgadas no site Couchsurfing (www.couchsurfing.com/about/about-us) em maio relevantes entre culturas nos permite responder à diversidade com curiosidade, apreciação e respeito. A valorização da diversidade difunde a tolerância e cria uma comunidade global. ${ }^{3}$

Os princípios estabelecidos pelo uso comum da RSV Couchsurfing esboçam diretrizes que se concretizam - ou, deveriam se concretizar - no âmbito das práticas sociais, também off-line. Estas, se iniciam nos próprios pedidos de hospedagem:

Compartilhe sua vida: Couchsurfing é sobre compartilhar a própria vida, as experiências, jornadas, sua própria casa, suas amêndoas extras ou um majestoso pôr do sol. Acreditamos que o espírito de generosidade, quando aplicado plenamente, pode resultar em uma mudança profunda do mundo.

Crie conexões: $O$ ato de conectar nos faz mais felizes. Precisamos mais disso. Conectar e aceitar a bondade de "estranhos" fortalece a fé um no outro, a fé recíproca, e nos ajuda a tornar-nos pessoas melhores.

Ofereça bondade: Tolerância, respeito e valorização das diferenças são incorporadas pela bondade.

Mantenha-se curioso: Prezamos e compartilhamos o desejo de aprender uns sobre os outros, aprender sobre o mundo e sobre como podemos crescer como pessoas e nos tornar cidadãos melhores para o mundo por meio da viagem.

Deixe-o melhor do que encontrou: Isso se aplica ao mundo, aos relacionamentos, à casa do seu anfitrião ou ao caminho que você toma para ir à cafeteria. Estamos aqui para melhorar o mundo, melhorar a vida uns dos outros e nos tornar mais fortes nessa intenção

de 2017. Neste artigo elas foram traduzidas de forma livre. 
de união. ${ }^{4}$

Nessa interação mediada pelas novas tecnologias, o que leva um anfitrião a receber um hóspede, por meio do Couchsurfing? Quais são os interesses que mobilizam um "surfer" a solicitar hospedagem em Jaguarão, no extremo sul do Brasil? Essas foram algumas das indagações feitas aos voluntários durante as entrevistas, conforme será abordado na sequência.

\subsection{Entre o real e o virtual: o paradoxo da soleira}

Alain Montandon, no prefácio d'O livro da Hospitalidade (2011) revela a soleira das portas, onde normalmente encontram-se tapetes, a porta principal e campainhas que dão acesso às residências. A soleira seria, assim, uma fronteira entre o interior e o exterior da residência onde novas condições e regras se descortinam para ambientar os hóspedes em um ambiente desconhecido. Buscou-se, nesse sentido, compreender os significados da "soleira" para os usuários jaguarenses do Couchsurfing e conhecer as razões pelas quais os usuários se cadastraram nessa rede.

O primeiro anfitrião entrevistado foi Storck, um jovem universitário de Manhuaçu, Minas Gerais, que mudou-se para Jaguarão em 2013 com a finalidade de estudar e, desde então, mantém seu cadastro na rede de viajantes. Em seu perfil como surfer ele destacou que "[...] acredita no poder do plural e é compartilhando e trocando experiências que se constrói um caráter e uma personalidade melhor." Na entrevista, ele acrescentou a finalidade principal de seu cadastro no site:

Sou estudante de Produção e Política Cultural da Universidade Federal do Pampa e trabalho com o teatro de forma intuitiva. O Couchsurfing, inclusive, é fundamental para interagir com pessoas diferentes, o que auxilia minha formação nesse sentido. (Storck, mineiro, 30 anos).

Esse relato ressalta, em certa medida, os princípios do Couchsurfing, e coincidem com possibilidades de criar e gerar conexões significativas com pessoas e lugares, com o adendo de ampliação de conhecimentos artísticos. As conexões mediadas pelo Couchsurfing estabelecem-se na medida em que anfitriões convertem-se em hóspedes, em determinadas situações, em que os papéis se alternam, infindavelmente. Segundo Camargo (2008, p.7) "[...] a hospitalidade é o ritual básico do vínculo humano (...)" e o vínculo, no Couchsurfing, se dá, entre outras formas, nesta alternância de papéis.

Storck possui a melhor reputação anfitriã em Jaguarão, que consiste em várias referências positivas deixadas pelos visitantes que passaram por sua residência. Para Cherney (2014), a reputação de um surfer é fundamental para o estabelecimento de laços de confiança, além de ser fator

4 Informações divulgadas no site Couchsurfing (www.couchsurfing.com/about/about-us) em maio de 2017. 
primordial durante a busca online por um host. Storck, ao ser indagado sobre sua marca principal e o que motiva os surfers a solicitarIhe hospedagem, responde que sua marca principal seria o fato de ele ser "livre de preconceitos e julgamentos". A confiança, assim, é edificada e nutrida a partir da reputação, fazendo com que futuros guests queiram se hospedar na casa de Storck.

Nessa mesma linha, a anfitriã Fafá, também estudante de Produção e Política Cultural, ressalta que não apenas o fato de morar em Jaguarão, mas também “a convivência com guests uruguaios e argentinos facilita muito o aprendizado do espanhol", e já o considera como sua segunda língua.

O Couch é muito dinâmico, tem muitas oportunidades. Uma vez, recebi um colombiano que não falava português direito. Daí tive curiosidade de aprender a falar espanhol, para abrir, sabe, poder receber melhor as pessoas. Desde então, eu tenho usado muito um grupo de aprendizado de língua espanhola na internet, tanto que eu já falo espanhol. Isso ajuda muito com meus hóspedes. (Fafá, paulista, 22 anos).

Esses primeiros depoimentos evidenciaram os diferentes e até antagônicos interesses relacionados à adesão dos surfers à rede. O anfitrião Leo, outro estudante entrevistado, chamou a atenção pelo gosto por fotografias. O mesmo expôs os motivos variados que despertaram seu interesse pelo Couchsurfing, atentando, também, para a constituição de novas amizades:

Eu entendo o Couchsurfing como uma plataforma de liberdade que traz novos olhares sobre o mundo [...], e também para o cotidiano. É como falar de fotografia onde cada fotógrafo tem sua lente, sabe, seu olhar. Eu fiz meu cadastro atrás de pessoas amantes da fotografia, da viagem, do inusitado, sabe? Atrás de amizade também, que goste do que eu gosto. (Leo, mineiro, 29 anos).

Para esse host, receber hóspedes em sua residência que sejam atraídos pelas mesmas vocações que ele, como a fotografia, ou simplesmente gostar de experiências inusitadas representa um filtro de aceitabilidade para seu "sofá", revelando que a abertura para a hospitalidade pode estar relacionada com algum interesse específico.

Carlito é professor de matemática e compartilha esse ideal condicionado da hospitalidade. Ao ser indagado sobre o processo pelo qual usualmente navega pelo site e aceita pedidos de hospedagem pelo Couchsurfing, salienta:

Leio o texto inteiro o máximo que eu
posso, pelo menos vejo as fotos e olho
se a pessoa é legal e vejo se tem alguma
coisa em comum, se a pessoa anda de
bicicleta, se ela tem um gosto comum
comigo por bicicleta. Eu gosto de
cozinhar e se a pessoa também gosta de
cozinhar, então, eu vejo essas coisas
assim. (Carlito, gaúcho, 27 anos).

Para esse anfitrião, 0 fato dos prováveis hóspedes terem gostos similares aos seus facilita a interação, tornando-se um requisito para a aceitabilidade dos pedidos e, em sequência, da acolhida dos hóspedes. Constata-se, aqui, que Leo e Carlito deixam clara uma posição que condiciona a hospitalidade em suas residências a uma regra. Esta diz respeito aos seus estilos de vida, que envolvem o gosto por fotografia no caso de Leo (mineiro, 29 anos) e por pedalar 
e cozinhar, no que se refere a Carlito (gaúcho, 27 anos).

Como sublinham Mauss e Hubert (2005), a dádiva pode envolver sacrifício e renúncia. Muitas vezes o sacrificante abre mão de interesses e atividades desempenhadas no cotidiano em função da doação de seu espaço e, também, de seu tempo. Nos relatos anteriormente apresentados, contudo, a noção de dádiva como forma de sacrifício, a princípio, não é cogitada pelos surfers Leo e Carlito. Seus estilos de vida, gostos e preferências são um critério de aceitabilidade de hóspedes e aqueles que não compartilhem seus interesses, são recusados. Além disso, "a obrigação de convidar as pessoas é inteiramente evidente quando se exerce de clã a clã ou de tribo a tribo" (Mauss, 1974, p.246).

Por outro lado, os surfers possuem em seus perfis o termo Accepting guests ativo e escolhem seus guests a partir da consolidação de filtros de aceitabilidade, o que não condiz com os valores da RSV expostos no site. Segundo a visão do Couchsurfing, é importante responder à diversidade com curiosidade, apreciação e respeito.

Uma jovem estudante de Letras natural de Manaus, no estado do Amazonas, reside sozinha e ressalta que após conversar com os colegas da universidade resolveu se cadastrar também na rede. Segundo ela, seu perfil no site do Couchsurfing é "[...] sempre ativo, movimentado, com muita gente diferente solicitando hospedagem." A jovem revela que é:

[...] fascinada por tudo que diz respeito a viagens, conhecer pessoas diferentes e tal. Conheci o Couchsurfing aqui no Rio Grande do Sul. A surpresa de cada hospedagem mostra um pouco do universo que é cada um e como é o mundo lá fora. Mas eu gostaria de viajar mais, só que não tenho condições financeiras nem para ir em casa nas férias, quanto mais para viajar por lazer. Assim, se não posso ir ao mundo, faço ele vir até mim. (Guru, 21 anos, amazonense).

Guru ponderou que busca, como anfitriã do Couchsurfing, oportunidades novas para viajar, ampliar os contatos e, quem sabe, "até conseguir um bom emprego após me formar?" (GURU, amazonense, 21 anos). Nesse mesmo sentido, a hóspede FlavNav, uma gaúcha de 33 anos que vive em Edimburgo, também entende a formação dessa rede como uma oportunidade na vida profissional:

O legal do Couchsurfing não é você ficar de graça na casa de alguém, é a conexão que tu fazes, é conhecer gente que às vezes trabalha na mesma área ou em uma área similar, né! E que pode gerar frutos, pode gerar colaborações na vida pessoal e profissional. (Flavnav, gaúcha, 33 anos).

Outros surfers corroboram os valores marcados pela rede Couchsurfing, que visam o compartilhamento de experiências, a criação de conexões, além da tolerância e respeito às diferenças, como já esclarecido. Eles ensejam esses valores quando dizem:

\footnotetext{
Sou baiana, mas moro em Jaguarão para estudar. Eu sempre valorizei muito conhecer novas culturas e fazer novos amigos. O Couchsurfing é fantástico, né, e hoje posso dizer que tenho muitos amigos graças a ele. (Minervina, baiana, 28 anos).
} 
(...) acredito que eu não consigo mais ficar sem o Couchsurfing na minha vida. Nele, eu tenho minha agenda de contatos, meus amigos de diversas partes do mundo. Gente que come carne e gente que não come, que bebe e que não bebe, que fala inglês e que não fala, e tal. É incrível como tem muita gente com trejeitos, linguagem, manias diferentes que comungam de um mesmo pensamento e gosto por viajar. (Bee, gaúcho, 24 anos)

Na verdade, eu sou carioca da gema, minha mãe mora no Rio e eu vivo em Jaguarão com meu pai, que é um uruguaio, de Río Branco. Sou do mundo. As pessoas fazem contato através da rede e quando chegam viramos a noite conversando, então, conversamos bastante. É uma boa oportunidade para conhecer as pessoas. (Bird, carioca, 22 anos).

No Couchsurfing, a representação da soleira parece não ter relação com as portas, com o sofá, com a "sala de estar" ou com quaisquer outros cômodos físicos existentes nas residências. Considerando as respostas dos surfers sobre os interesses pela rede de maneira geral, as descrições relacionadas às suas filosofias de vida, motivações, referências e reputação, indicam que o entendimento de soleira remete a um "ritual de iniciação" para os sujeitos pesquisados. A soleira, nesse caso, tem início em um ambiente virtual no qual o futuro hóspede solicita sua própria hospedagem escolhendo um entre vários hosts disponíveis, a princípio, para hospedá-lo.

É nesse contexto que os anfitriões transpõem suas soleiras e navegam entre os surfers, percebem suas filosofias e particularidades como idade, condição civil, imagens e outras características. Buscam, dessa forma, ajustar critérios em um movimento no qual a soleira se torna pendular e se arrasta pelos parâmetros de escolhas, negativas às solicitações de hospedagem ou aceite dos surfers. Mas, o que motiva as pessoas a se deslocarem a Jaguarão/RS, utilizando o Couchsurfing?

Os estudos em turismo e
hospitalidade costumam estudar as motivações de viagem enquanto base para as pesquisas de demanda turística. A Organização Mundial do Turismo (OMT) indicou, em 2008, grupos motivacionais, observáveis a partir das atividades desempenhadas no decorrer das viagens. As motivações de turismo são agrupadas em oito grupos: a) Lazer, recreação ou férias; b) Visita a parentes ou amigos; c) Negócios ou motivos profissionais, incluindo os estudos; d) Tratamento de saúde; e) Religião e Peregrinação; f) Compras; g) Visitantes em trânsito e h) Outros motivos (OMT, 2008).

Sob outra perspectiva, Swarbrooke \& Horner (2002), e Pearce (2001) empenharam-se em conciliar os fatos observáveis, decorrentes das ações desempenhadas no dia a dia do turista, em determinado destino, aliados à profundidade do ser. Boullón (2004), por sua vez, traçou razões combinadas que levam os sujeitos a se deslocarem em viagem.

Em relação aos guests investigados, foi comentado o seguinte:

Eu gosto muito do Couchsurfing, de viajar, conhecer outras culturas. Por onde andar levo um pouco do que aprendi na Índia: dignidade humana. Minha prima mora na cidade de Melo, no Uruguai, assim eu resolvi passar por Jaguarão para passear e conhecer um pouco mais do Brasil e também porque minha prima encomendou umas coisas 
do free shop. Mas, fiquei apenas uma noite pelo Couchsurfing e estava mesmo de passagem. (Bitmary, mexicana, 26 anos)

Não tenho namorada e sempre tinha o sonho de conhecer a América Latina, bem inspirado mesmo nos caminhos do Che Guevara, como no filme. Larguei de mão o trabalho na Itália e fui realizar meu sonho. O Couchsurfing fez o roteiro se materializar, claro, passando por Jaguarão, Lagoa Mirim e seguindo rumo a Montevidéu e, também, Argentina e Chile. (Teo, italiano, 31 anos).

Como é possível verificar nesses relatos, não há um único motivo para que Bitmary e Teo se deslocassem até Jaguarão. Ambos estariam de passagem, como "visitantes em trânsito" (OMT, 2008; Boullón, 2004). No entanto, ao mencionar os verbos infinitivos "passear" e "conhecer", nota-se que a surfer também estava disposta a viver outras experiências de lazer, e não somente "passar por Jaguarão".

Outro adendo refere-se aos produtos de free shops encomendados a Bitmary, caracterizando também a motivação de "compras" (OMT, 2008; Boullón, 2004), na justificativa de sua permanência na cidade. Ao expor seu interesse por empreender o roteiro fílmico de "Diários de Motocicleta", Teo esboça motivação cultural que pode estar assentada em objetivos diversos, como a própria realização de um sonho. Outras características motivacionais surgem através da apresentação dos seguintes relatos:

Foi uma surpresa porque realmente eu não esperava encontrar alguém que tivesse Couchsurfing em Jaguarão e não esperava também encontrar tanta gente para uma cidade com o tamanho de Jaguarão, e localizada onde ela está. [...] fazia tempo que eu não usava e foi legal eu me conectar com a comunidade do Couchsurfing. Foram só duas noites que eu passei lá, só para ir no seminário para criação do comitê de políticas culturais entre Brasil e Uruguai. (Flavnav, gaúcha, 33 anos).

Eu fui conhecer a Lagoa Mirim. Sou da área de botânica, trabalho no parque nacional de Biebrza, na Polônia. Em 2009 conheci o Lago Titicaca, nos Andes, e lá fiz amizade com gaúchos que disseram que eu teria que conhecer a Lagoa Mirim. Pesquisando depois, eu percebi que é o segundo maior lago da América do Sul e pensei, preciso conhecer! Sou curioso e apaixonado pela profissão. (Pucek, russo, 42 anos).

Flavnav e Pucek expressaram, em comum, interesses ligados às suas profissões, diretora de teatro e guia de turismo, respectivamente. Embora exista um apelo profissional motivador dos "surfes de sofá" de ambos os guests, nota-se que Pucek apresenta razões culturais e educacionais para viajar a Jaguarão (Boullón, 2004), como se quisesse enriquecer sua atuação profissional.

Motivos diferentes dos já tratados foram enunciados pela mexicana Potosí. Ela explicou que seus amigos

[...] foram de moto para Jaguarão, para participar da Motofest, uma feira que reúne motoqueiros de toda a América Latina. Tive interesse em participar, mas não para ir de moto desde San Luís a Jaguarão (risos). Então eu programei as férias, fui para o Brasil e aproveitei para conhecer outros lugares também, como São Paulo e Porto Alegre. E me encontrei com a turma em Porto Alegre, segui de carona até Jaguarão. Gosto da sensação de liberdade e da energia do vento que vem na face. $E$ conhecemos 
Río Branco, Lago Merín e Melo, no lado uruguaio. (Potosí, mexicana, 26 anos).

Agregando-se as classificações anteriormente expostas, ressalta-se que Potosí também evidenciou motivações combinadas que dizem respeito, inicialmente, ao interesse por "lazer, recreação ou férias" (OMT, 2008), mas também para "conhecer" (Boullón, 2004) e acompanhar os amigos.

Importa, nesse artigo, reconhecer como o fator motivacional dos surfers pode ser influenciado pelos princípios do Couchsurfing e baseados na dádiva. A hospitalidade mediada pelo Couchsurfing incita, enquanto premissa coletiva de usabilidade pautada na reciprocidade, motivações coletivas pelo compartilhamento da vida, pela criação de conexões, pela oferta de bondade por onde se passa, pela apreciação das diferenças.

Em um primeiro momento, constatase que o pernoite de Bitmary em Jaguarão ressoou em conveniência, pois ainda que estivesse de passagem, ela não teria solicitado host se não tivesse encomendas dos free shops para levar à prima. Teo esteve de passagem por Jaguarão, pois, seguiria seu roteiro até o Chile, explicando que não o conseguiria sem o Couchsurfing. Pucek elegeu um elemento natural para motivar sua viagem, embora esteja implícita sua curiosidade profissional também. Flavnav destacou um compromisso profissional com programação intensa para dois dias. Por último, Potosí salientou um evento específico para usufruir o lazer com seus amigos mexicanos.
Encorajados por pretextos diversificados, os surfers não fizeram menção aos princípios "dar, receber e retribuir" enunciados pelo Couchsurfing e pela teoria da dádiva - quando foram indagados sobre os motivos pelos quais estiveram em Jaguarão. De toda forma, é essencial repensar as classificações quanto às motivações de turismo, pois, elas não conseguem sustentar a fluidez e a complexidade crescentes das práticas sociais vivenciadas no contexto atual.

\subsection{Os surfers e a composição das relações in lócus}

O tempo de permanência nos destinos costuma ser um aspecto relevante a ser observado quando se pensa em qualificar a demanda turística, ou seja, nos turistas. A permanência dos guests investigados foi de aproximadamente dois dias. Para a compreensão das atividades desenvolvidas entre os surfers durante o tempo de permanência dos hóspedes em Jaguarão, eles foram indagados sobre as atividades propiciadas durante as interações, tanto no interior quanto no exterior das residências, bem como sobre algumas situações que lhes chamaram a atenção.

As exposições dos anfitriões, assim como de alguns guests, revelaram que normalmente os hóspedes não possuíam quaisquer interesses em serem guiados pela cidade, embora, quase sempre, buscavam perambular pelas ruas, a sós. Acompanhados ou não pelo anfitrião, e até mesmo por meio de receptivos turísticos, os hóspedes não 
demonstraram ser uma prioridade conhecer Jaguarão, sua história e suas atrações.

Para Urry (2001, p.16), "não existe um único olhar do turista enquanto tal. Ele varia de acordo com a sociedade, o grupo social e o período histórico" em que se insere. $\mathrm{Na}$ pesquisa, foi possível perceber que as imagens deixadas na página do Couchsurfing de cada surfer investigado não possuem, como pano de fundo, atrativos turísticos conhecidos de Jaguarão/RS, como praças, avenidas, igrejas, arquitetura, entre outros.

No entanto, a host Fafá concedeu imagens que retratam a permanência guest e as interações que ali ocorreram no contexto de Jaguarão/RS. São imagens do "Beco do Papoco", uma "república" de estudantes que dividem o aluguel e as despesas da residência. Fafá, host pesquisada, é a única representante de sua comunidade de estudantes para as finalidades da pesquisa, uma vez que apenas ela possui cadastro na RSV. A imagem de uma das paredes da casa (figura 2) foi apresentada quando ela foi perguntada sobre o desfrute de seu tempo em relação às atividades desenvolvidas junto aos guests.

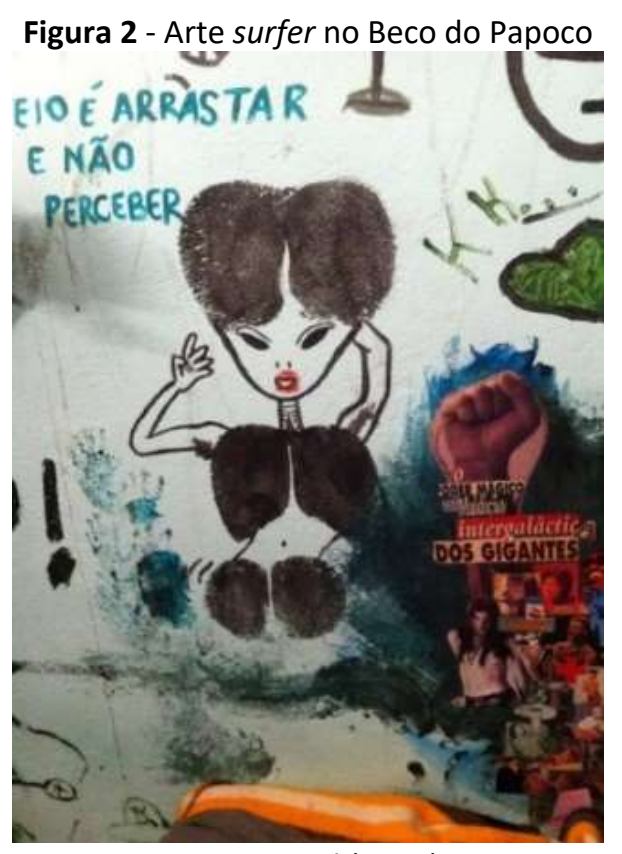

Fonte: Arquivo pessoal (2016)

Um turista geralmente estabelece as primeiras relações com o espaço por meio da estética, e isso também é marcado pelas percepções dos viajantes quanto às imagens publicadas na página virtual do Couchsurfing. Esse primeiro contato traz sensações e emoções que podem despertar o interesse em interagir de forma mais aprofundada ou gerar distanciamento e repulsa pelo espaço.

Fafá destacou que, quando recebe hóspede, normalmente passam o dia conversando, cozinhando e "fazendo arte". Eles falam sobre música, comida, diversão e arte. Como salienta essa anfitriã, em diversos 
momentos eles fazem "arte nas paredes do Beco". Para ela, os recados, desenhos e poemas impressos na parede pelos guests são uma boa lembrança e configuram um presente. A manutenção desses registros preocupa os estudantes que ali moram: "Teremos que entregar a casa, mas e as paredes? Será que teremos que pintar? Isso é arte e traz muitas lembranças." (Fafá, paulista, 22 anos).

\section{O relato anterior revela uma fusão de} sensações, em complexas interações. "Misturam-se as almas nas coisas, misturamse as coisas na alma. Misturam-se as vidas, e assim as pessoas e as coisas misturadas saem cada qual de sua esfera e se misturam: o que é precisamente o contrato e a troca". (Mauss, 2003, p.212). E isso se reflete na preocupação de Fafá em relação à parede, pois apagar os registros feitos por aqueles que ali viveram ou passaram revela uma quebra da premissa cíclica do dar, receber e retribuir, deixando os residentes confusos em relação a isso.

Essa mistura destacada por Mauss (2003) também foi percebida nos relatos dos surfers sobre como passam o tempo e o que fazem para promover a interação offline:

A gente começava a conversar, eles dormiam no quarto e na sala, a gente começava a conversa no café da manhã, fazia almoço, ficava a tarde inteira juntos, falando de pedal. [...] fazia janta, ficava até de madrugada bebendo, só rindo, rindo e rindo. (Carlito, gaúcho, 27 anos)

Você ir ao centro e andar, então a pessoa acaba conhecendo só indo no centro, por ser pequeno também. Então, as pessoas que vêm aqui, a gente tem vontade mesmo, "vamos ali no rio e tal", "vamos no Uruguai", "vamos nos free shops", a gente quer mostrar tanto a parte turística do local, quanto a parte histórica também, mas nem sempre eles querem pôr os pés para fora de casa. (Leo, mineiro, 29 anos)

As pessoas vêm aqui e acabam não querendo sair daqui de casa, porque ficam tão felizes, ou até mesmo deslumbradas com isso tudo, com as pessoas conversando e não só dando aquele auxílio, mas conversando e é muito legal isso, da pessoa vir esperando alguma coisa fora do aconchego de um hotel, com aquele "fru-fru" todo e chega aqui, fazemos um café, preparamos um mate, fumamos um cigarro, conversamos. (Minervina, baiana, 28 anos).

Sob outro ponto de vista, os comentários dos guests do Couchsurfing remetem ao tempo dispensado para conhecer um "pacote" de atratividades, bem como as principais diferenças por eles percebidas entre as viagens proporcionadas pela rede, e as convencionais. Estas foram chamadas, por um dos viajantes, de turismo "risca da lista":

[...] a maioria das pessoas que têm condição de viajar, hoje em dia, principalmente eu vejo isso no Brasil, parece que tu tens uma lista, tipo aquela lista de coisas a fazer, que a gente vai riscando as coisas da lista. Até porque o tempo é curto para conhecer tudo, sabe, uma espécie de turismo risca da lista? (Flavnav, gaúcha, 33 anos)

Não foi uma viagem turística, mas sim um encontro na fronteira. Eu não estava com interesse em conhecer, porque eu acho que, eu acredito, que uma pessoa com interesses, ela vai chegar, se não tiver companhia, ela vai chegar com a mochila nas costas e vai sair, vai conhecer, ela vai fazer o seu check list e tal, e vai conhecer, mas eu não tinha interesse nos pontos turísticos da cidade. (Potosí, mexicana, 24 anos) 
De acordo com as ponderações de Bauman (1998, p.117), "as pessoas que o turista encontra no lugar visitado não são nada mais que encontros acidentais, sem nenhuma consequência futura", o que contrasta com o que foi constatado nesta pesquisa sobre uma rede de viajantes em Jaguarão, que disseram ter priorizado o estabelecimento de vínculos afetivos entre os anfitriões e hóspedes. Sobre isso, outro guest expressa: Tem gente que pensa: vou passar uma noite, com o objetivo de fazer turismo. Eu me considero como um viajante, não como um turista, aí pessoas vêm só para fazer turismo, tirar selfies e postar, só isso. (Pucek, russo, 42 anos)

Para Meireles (1999), um dos aspectos diferenciadores entre turista e viajante está relacionado àquilo que os mesmos buscam em sua viagem. Para a poetisa, enquanto o turista aprecia satisfação de ordem material (como tirar fotos, comprar presentes, desfrutar de hotéis), o viajante busca experiências espirituais, relacionada à contemplação da viagem, de maneira geral. Nas Teorias do Turismo, entretanto, essa diferenciação passaria pela resposta básica da questão "Qual o motivo de sua viagem?".

O turista "tradicional", enquanto invenção da modernidade (Bey, 1997), busca o desfrute de atrações materiais, como comentou uma das entrevistadas:

[...] vou lá porque eu tenho que ir, porque todo mundo foi, né! É mais essa coisa de eu tenho que postar, eu tenho que mostrar e compartilhar minha experiência do que ter a experiência em $\mathrm{si}$, diferentemente do que o
Couchsurfing proporciona [...]. (Bitmary, mexicana, 26 anos)

Em contrapartida, o viajante busca outros prazeres, uma vez que ele não utiliza, por exemplo, todo o sistema turístico disponível e oferecido no destino, os quais representam a infraestrutura, os equipamentos e os atrativos naturais $e$ culturais previamente catalogados e divulgados nas mídias. Ele busca a contemplação, o estabelecimento de laços com o destino e seus moradores. Gomes et al. (2007) ressaltam que o turismo deve ser visto como uma experiência humana e social. Nesse sentido, o próprio turismo pode consistir em viagens que buscam o reconhecimento do outro e de si, antes desconhecido e longínquo. Os lugares são "núcleos de valor" e permitem a vivência de experiências, meio de conhecimento e construção da realidade.

Outros entrevistados, entre anfitriões e hóspedes, fixaram os olhares pela fronteira e sobre suas atrações turísticas mais significativas, ao se conduzirem pela questão que abrange o cotidiano, o que fazem durante o período de permanência dos hóspedes junto às residências dos anfitriões.

\footnotetext{
A gente sempre parava e olhava a paisagem e, para mim, a primeira coisa quando eu cheguei na cidade foi ir à Ponte Mauá. Eu pensei: “Nossa, isso aqui é muito diferente", porque estava um calor extremo e foi uma sensação bem bacana de estar num local que, no outro lado, na realidade é um outro país totalmente diferente, uma cultura totalmente diferente e estar parado ali com o rio passando é uma coisa meio bucólica também. (Teo, italiano,31 anos)
} 
Jaguarão é uma cidade bastante histórica, tem prédios muito bonitos e pontos históricos bacanas, a gente acabava levando os convidados para conhecer esses locais, conhecer algumas pessoas, alguns eventos assim e eles adoravam, eles ficavam encantados com a enfermaria militar, a ponte, as igrejas, e é muito bacana. (Guru, amazonense, 21 anos)

Quando me pedem eu apresento a rua 15 de novembro, que é conhecida como a rua das portas, mais artística, e depois a igreja da Minervina Correia, a matriz, a enfermaria militar, arquitetura da ponte vista de baixo e de cima, o mercado central que está em reforma, a praça dos Escravos, o largo das Bandeiras, as praças é mais isso mesmo, esses pontos mais principais, o regente, o teatro Esperança. (Fafá, paulista, 22 anos)

Acho que era verão e aí eles falaram que depois de um tempo eles ficaram assistindo o pôr do sol lá do lado do Uruguai, ali onde tem aqueles banquinhos, atrás dos free shops, de frente para o rio, ficaram ali. (Bird, carioca, 22 anos)

Como percebe-se nesses relatos, no contexto de uma rede virtual de viajantes como o Couchsurfing, em Jaguarão, as experiências de lazer são fundamentais para a hospitalidade, pois propicia trocas entre os surfers, tanto anfitriões quanto hóspedes. Outro aspecto a ser destacado é que a tríade "dar, receber e retribuir" está presente no depoimento da maioria dos entrevistados que, desde o contato estabelecido através da RSV, valorizaram a reciprocidade. No paradigma virtual, a soleira foi transposta no momento da "virada da chave", ao se passar do modo offline para o online, ajustando login e senha na RSV Couchsurfing, navegando ou "soleirando" por entre "as casas" (perfis) de outros surfers.

Mauss (2003) atentou ao simbolismo da troca entre os andamaneses, que são considerados muito hospitaleiros. Entre eles, persiste uma maneira lúdica de acolher, além da retribuição de base voluntariosa, embora obrigatória (Mauss, 2003). Essa exemplificação pode ser relacionada com o estudo aqui apresentado, sob a premissa de que o Couchsurfing pode ser uma troca advinda da hospitalidade, com conotações que remetem ao coletivo quando as viagens são baseadas nas trocas e na generosidade.

Tais constatações são notórias nas interações offline entre hóspedes e anfitriões em que, no contexto pesquisado, destacamse as oferendas de refeições, as mateadas, os cozidos do jantar, como dádivas que complementam a hospedagem doada pelos hosts. Em contrapartida, os guests, em determinados momentos, recebiam e procuravam retribuir a hospitalidade de alguma forma ainda durante sua estadia na residência, enquanto "gesto de compensação" (Grassi, 2011, p.45). Isso foi comentado por uma guest:

Ela sempre estava na cozinha. Ela é de
São Paulo e tem outros moradores no
Beco, de outros lugares. Eles
compraram carne para o churrasco.
Acontece que sou vegetariana e logo
voltaram ao mercado para buscar
legumes, foram muito compreensivos e
receptivos. Fui com eles e comprei a
bebida. (Potosí, mexicana, 26 anos)

A iniciativa de "presentear" e a generosidade implícita nesse gesto conduzem à obrigação da retribuição que, embora esteja relacionada à moral do 
donatário, é identificada por Mauss (2003) como uma vantagem, um interesse econômico. Nesse sentido, Mauss (2003) faz diversos apontamentos que vão colidir com os argumentos sobre as motivações humanas por estarem além da moral. Conforme o autor argumenta, a moral pode ser diferente de uma sociedade para outra, mas vai ao encontro dos compromissos simbólicos da tríade dar, receber e retribuir.

Como já aludido anteriormente, mesmo que algumas experiências sejam apontadas como negativas, os adeptos do Couchsurfing abstêm-se de seus julgamentos para continuar na experiência, valorizando um sistema de reciprocidade de caráter interpessoal. Potosí complementa:

[...] realmente saí com a sensação de ter feito amigos ali, gente que mesmo que a gente não se fale com frequência, agora eu sei que eles estão lá e eles sabem que eu estou aqui, então pode rolar alguma colaboração em algum momento né? Pode ser que aconteça algum dia um deles vir para o México. Eu chamei para ficarem na minha casa. (Potosí, mexicana, 26 anos)

Em contrapartida, existem "trocas e trocas". Chamou a atenção o depoimento abaixo:

E quando meu host percebeu que eu estava cheia de garrafas de vinho e bolsas dos free shops, logo veio pedir uma colaboração financeira para ajudar com sua despesa de água e luz. Fiquei espantada, isso nunca me ocorreu. (Bitmary, mexicana, 26 anos)

As trocas advindas das relações entre os surfers exprimem uma diversidade de simbologias. Ao mesmo tempo, assumem caráter interno, afetivo, pautados em sentimentos de amizade e generosidade, mas que também revelam a inexistência de um sacrifício para que ocorram. Para Camargo (2006), a hospitalidade é conferida à abordagem dos espaços e das pessoas. No momento em que essa hospitalidade revoga o sacrifício implícito em suas práticas, então não se trata de hospitalidade inspirada na dádiva. É uma hospitalidade "teatralizada", como lembra Gotman (2001).

Um exemplo disso é o fato do host de Bitmary ter solicitado uma "colaboração financeira" por sua estadia, sob a alegação de contribuir com as despesas da casa. Segundo o depoimento, a guest acabou por assumir um contrato em que há, meramente, uma troca e que, segundo Camargo (2006), desarmoniza e não esboça princípio algum de hospitalidade.

Gotman (2009) explica a relação assimétrica da hospitalidade gratuita como um aspecto concebido pela dádiva. Por esse lado, uma questão a considerar é que a troca monetária, também como em contratos de meios de hospedagem, interfere nessa assimetria da hospitalidade. No caso de Bitmary, o pagamento pela hospitalidade em Jaguarão, que, segundo ela custou $\mathrm{R} \$ 40,00$, a deixou em situação de igualdade de seu anfitrião, descaracterizando a conduta sugerida pelo site de "Não cobrar pelo sofá".

$O$ anfitrião é autônomo no interior de sua residência, uma vez que está, territorialmente, em posição superior ao hóspede (Gotman, 2009). No momento em que existe uma relação monetária, determinada pelo pagamento financeiro pelo uso do espaço e até pelas relações e 
interações sociais existentes no interior da residência, há propensão à simetria da hospitalidade, como ocorre em hotéis. Essa simetria evoca uma posição de igualdade entre anfitrião e hóspede no ambiente doméstico, destoando da hospitalidade baseada na dádiva.

\section{CONSIDERAÇÕES FINAIS}

Este artigo buscou identificar e discutir os principais interesses e motivações pela rede e pelas viagens Couchsurfing, entre os anfitriões e hóspedes jaguarenses, bem como compreender o sistema de trocas entre ambos. Essa discussão foi guiada pelos estudos da hospitalidade baseados na Teoria da Dádiva, de Marcel Mauss.

A partir das associações estabelecidas com os estudos de Mauss (2003), infere-se que a troca, no contexto da pesquisa sobre a hospitalidade jaguarense mediada pelo Couchsurfing, é iniciada a partir do momento em que se escolhe um perfil e se faz a solicitação para ficar hospedado, ou seja, ainda online. A partir daí, cria-se um compromisso da dádiva mútua, revelada pela consciência ou compromisso moral, de anfitriões e hóspedes, em dar, receber e retribuir hospitalidade. Na fronteira dessas inter-relações, situa-se a fronteira virtual entre anfitriões e hóspedes no extremo Sul do Brasil.

Sobre as motivações para que esses surfers se envolvam com o Couchsurfing em Jaguarão, a pesquisa constatou que os interesses são variados. Os deslocamentos têm por finalidade desde fazer compras nos free shops, visitar parentes, desenvolver interesses profissionais, até mesmo desfrutar - lazer em períodos de férias. Indiscutivelmente, os guests não fizeram menção a interesses coletivos referenciados pela tríade "dar, receber e retribuir", implícita nos princípios do Couchsurfing. Isso foi salientado, em outros trabalhos, como uma qualidade dos membros desta RSV, como afirmado autores como Bialski (2007) e Figueiredo (2008), por exemplo.

Dentre os sistemas de trocas analisados constatou-se um episódio envolvendo troca monetária, nos moldes da locação hoteleira tradicional. Revelada pelo comentário de uma host, a assimetria da hospitalidade equipara as mesmas condições de pertencimento do espaço no interior das residências, entre hóspede e anfitrião. Esse traço assimétrico enaltece o caráter contratual da hospitalidade (Camargo, 2006), mas não apresenta uma característica da RSV analisada.

Por outro lado, o oferecimento, pelos hosts, de refeições, passeios e "mateadas" como presentes que extravasam uma simples hospedagem, muitas vezes era compensado por retribuições imediatas por parte dos guests. Alguns deles compravam bebidas para o jantar e deixavam poemas, lembranças e desenhos nas residências, caracterizando a troca simbólica fundamentada pela tríade dar, receber e retribuir (Mauss, 2003).

É basilar acrescentar que, em oposição a um número crescente de estudos relacionados às demandas turísticas nos destinos, esta pesquisa focou tanto anfitriões como hóspedes e apontou uma peculiaridade de Jaguarão no que se refere 
ao primeiro grupo. Afinal, de forma semelhante ao que ocorre com os hóspedes, os anfitriões jaguarenses compõem uma população flutuante local, formada por estudantes da UNIPAMPA. As práticas sociais do Couchsurfing em Jaguarão permitiram, assim, a compreensão da hospitalidade e das trocas embasadas na teoria de Marcel Mauss, a partir dos posicionamentos e características dos surfers pesquisados, que, notoriamente em maioria, não são naturais do município (e nem do estado do Rio Grande do Sul).

As RSVs aliadas ao fluxo de informações correntes em seu âmago configuram o modus vivendi da sociedade contemporânea. Contudo, tornam-se imperativas novas instrumentalizações empíricas arroladas sob diferentes circunstâncias e que harmonizem-se à liquidez das práticas sociais em ascensão, tanto em termos de Lazer como de Turismo e Hospitalidade.

\section{REFERÊNCIAS}

Alves, V. H. (2011). A chave que desliga a Internet. Revista.br.. São Paulo, n. 4, ano 3, p. 22-23. Bauman, Zygmunt. (2003). Comunidade. Rio de Janeiro: Jorge Zahar.

. (1998). Globalização: As Consequências Humanas. Rio de Janeiro: Zahar.

Bey, Hakim (1997). Sedução dos Zumbis Cibernéticos. 1997.

Bialski, Paula. (2012). Becoming Intimately Mobile. Warsaw: Warsaw Studies in Culture and Society, v.2.
. Intimate Tourism: Friendships in a State of Mobility-The Case of the Online Hospitality Network. (2007). 86f. Dissertação. (Mestrado em Sociologia e Psicologia Social). Instituto de Sociologia, Universidade de Varsóvia, Varsóvia, 86f.

Bialski, Paula; Batorski, D. (2010) From Online Familiarity to Offline Trust: How a Virtual Community Creates Familiarity and Trust between Strangers. In: Zaphiris, P.; Ang, C. S.(Org.). Social Computing and Virtual Communities. Boca Raton: Taylor and Francis Group, 2010. p. 179-205.

Boullón, R. C. (2004). Atividades turísticas e recreativas. O homem como protagonista. Bauru: Edusc.

Bradbury, R. L. (2013). Couchsurfing in North Texas: a Localized View of a Global Phe-nomenon. 2013. 131f. Dissertação (Mestrado em Sociologia da arte), Universidade de Texas, Arlington.

Camargo, L. O. L. (2006). "Hospitalidade sem sacrifício? O caso do receptivo turístico". Revista Hospitalidade, São Paulo, n. 2, 2006, p. 11-28.

Apresentação à Edição Brasileira: O estudo da hospitalidade. (2011). In: Montandon, Alain (org.) O Livro da hospitalidade: acolhida do estrangeiro na história e nas culturas. São Paulo: Senac São Paulo, 1437 p.

. A pesquisa em Hospitalidade. (2008). Revista Hospitalidade, ano V, n. 2, p 23-56.

Hospitalidade. (2004). São Paulo: Aleph.

Castells, Manuel. (2003). A galáxia da internet: reflexões sobre a internet, os negócios e a sociedade. Rio de Janeiro: Jorge Zahar Ed.

Cherney, M. R. (2014). Surf's Up: Communicative aspects of online trust-building via re-ducing uncertainty online in Couchsurfing. Illinois State University. 
Couchsurfing. (2013). Disponível em: $<$ http://www.Couchsurfing.org>.

Cunha, Aline Moraes. (2012). O artesanato, suas estratégias de comercialização e cons-tituição enquanto produto turístico da agricultura familiar em Pelotas, Pedras Altas e Jaguarão - RS: os casos do ladrilã e das redeiras. Dissertação. UFRGS.

Dutra, Mariana. (2010). Turismo 2.0: um estudo de perfil de usuários da rede Couchsurfing. Monografia. Universidade Federal do Rio Grande do Sul, Porto Alegre.

Figueiredo, Ana Flávia de A. (2008). Sobre buscas e sentidos em uma rede mundial de viajantes: The Couchsurfing Project. Dissertação. Universidade Federal de Pernambuco. Recife. 122p.

Godbout, Jacques T. (1999). O espírito da Dádiva. Colaboração de Alain Caillé. Rio de Janeiro: Fundação Getúlio Vargas.

Godelier, Maurice. (1996). L'inigme du don. Paris: Librairie Artheme Fayard.

Gomes, Christianne L. et al. (2007). Turismo e lazer: reflexos no contexto da pós-graduação stricto sensu, nessa área, no Brasil. In: Seminário da Associação Brasileira de Pesquisa e Pós-graduação em Turismo. São Paulo: Aleph.

Gotman, Anne. (2001). Le Sens de I'hospitalité. Paris: Presses Universitaires de France.

Gotman, Anne. (2009). O comércio da hospitalidade é possível? Revista Hospitalidade. São Paulo, v. VI, n. 2.

Grassi, Marie-Claire. (2011). Hospitalidade: Transpor a soleira. In: Montandon, Alain (org.) $O$ Livro da hospitalidade: acolhida do estrangeiro na história e nas culturas. São Paulo: Senac, São Paulo. 1437 p.

Hine, C. (2005). Virtual Methods and the Sociology of CyberSocial-Scientific Knowledge. In: C.
Hine (org), Virtual Methods. Issues in Social Research on the Internet. Oxford: Berg.

IBGE. (2017). Instituto Brasileiro de Geografia e Estatística. Disponível em: <http://ibge.gov.br>.

Kozinetz, Robert. V. (2014). Netnografia: Realizando pesquisa etnográfica online. Porto Alegre: Penso.

Lashley, Conrad; Lynch, Paul; Morrison, Alisson. (2006). Hospitality: a social lens. Oxford: Elsevier. Advances in Tourism Research Series.

Laville, Christian; Dionne, Jean. (1999). A construção do saber: manual de metodologia da pesquisa em ciências humanas. Belo Horizonte: UFMG.

Liu, X. (2013). Social Networking Sites 'Influence On Travelers' Authentic Experience A Case Study Of Couch Surfing. Middle Tennessee State University.

Mauss, M. [1923-24]. (1974). Ensaio sobre a dádiva. Forma e razão da troca nas sociedades arcaicas. In: Sociologia e Antropologia. v. II. São Paulo: Edusp.

(1950). Sociologia e Antropologia: o ensaio sobre a dádiva. São Paulo: Cosac \& Naify.

(2003). Sociologia e antropologia. São Paulo: Cosac \& Naify.

Mauss, M. \& Hubert, H. (2005). Sobre o sacrifício. S. Paulo: Cosac Naify.

Maingueneau, D. (2000). Termos-chave da análise do discurso. Belo Horizonte: UFMG.

Meireles, Cecília. (1999). Crônicas de viagem. Rio de Janeiro: Nova Fronteira, v.3.

Montandon, Alain (org.) (2011). O Livro da hospitalidade: acolhida do estrangeiro na história e nas culturas. São Paulo: Senac: São Paulo, 1437 p. 
OMT. International Recommendations for Tourism Statistics. (2008). Nova lorque: Autor. Disponível em: <http://statistics.unwto.org/en/content/international-recommen-dations-tourismstatistics-2008-irts-2008>. Acesso em: 14 ago. 2017.

Panosso Netto, Alexandre. (2013). O que é turismo. São Paulo: Brasiliense.

Perrot, Danielle. (2011). Dádiva: Hospitalidade e Reciprocidade. In: Montandon, Alain (Org.) O livro da hospitalidade: acolhida do estrangeiro na história e nas culturas. São Paulo: Senac: São Paulo, $1437 \mathrm{p}$.

Polivanov, Beatriz. Etnografia Virtual, Netnografia ou Apenas Etnografia? Implicações dos Termos em Pesquisas Qualitativas na Internet. (2013). Intercom - Sociedade Brasileira de Estudos Interdisciplinares da Comunicação XXXVI Congresso Brasileiro de Ciências da Comunicação. Anais. Manaus.

Prefeitura Jaguarão. Disponível em: $<$ http://www.intercom.org.br/papers/nacionais/2013/resumos/R8-0346-1.pdf>. Acesso em: 14 ago. 2017.

Ribeiro, M. F. B. , Melo, A. (2011). Centro de Interpretação do Pampa: Jaguarão - RS. Espaços Culturais e turísticos em países lusófonos: cultura e turismo. Rio de Janeiro: UFRJ/FAU/PROARQ.

Ronzhyn, A. Literature Review of Couchsurfing Research. Disponível em: <http://ronzhyn.com/files/cs_review.pdf>. Acesso em: mar. 2016.

(2015). Trust and Tolerance in Online Hospitality Networks. University of Deusto.

Stern, Raquel Farias. (2009). Turismo e Pós Modernidade: Uma Análise do Intercâmbio de Hospitalidade - o caso do Couchsurfing. Revista Itinerarium. Rio de Janeiro, 141p. v.2, 2009. UNIRIO. Disponível em: <http://www.seer.unirio.br/index.php/itinerarium/ar-ticle/viewArticle/387>. Acesso em: 14 ago. 2017.
Shapiro, J. D. (2012). "Couchsurfing": Explorations in Cosmopolitanism, Trust, and Re-sistance. ProQuest Dissertations and Theses. University of California, San Di-ego, Ann Arbor.

Swarbrooke, John; Horner, Susan. (2002). O comportamento do consumidor no turismo. São Paulo: Aleph. 405 p. (Série turismo).

Urry, John. (2001). O olhar do turista: lazer e viagens nas sociedades contemporâneas. São Paulo: Studio Nobel; SESC.

Vila, Trinidad Dominguéz; Vila, Noelia Araújo. (2012). El fenómeno 2.0 en el sector turístico. El caso de Madrid 2.0. Revista Pasos Online. v.10, n.3. Disponível em: <http://www.pasosonline.org/Publicados/10312/PA

SOS29.pdf\#page=9>. Acesso em: mar. 2015.

William, Edu; Martell, E. Pérez. (2008). Turismo 2.0. La web social como plataforma para desarroIhar um ecossistema turístico basado en el conocimiento. Estudios Turísticos. n.178, p. 113-147.

Yannopoulou, N. (2013). User-Generated Brands and Social Media: Couchsurfing and Airbnb. Contemporary Management Research. n. 9(1), p.8590.

Zhu, Y. (2010). Social Capital, Trust and the Online Hospitality Community. Manchester: University of Manchester.

Informações das autoras

\section{Marcina Amália Nunes Moreira}

Professora da Universidade Federal de Viçosa. Doutora em Estudos do Lazer (UFMG, 2017), Mestre em Geografia (UFMG, 2010), Especialista em Turismo e Desenvolvimento Sustentável (UFMG, 2007) e Bacharel em Turismo (Centro Universitário Newton Paiva, 2007). Membro do Grupo de Pesquisa LUCE - Ludicidade, Cultura e Educação (UFMG/CNPq). E-mail: marcina.amalia@ufv.br.

ORCID: http://orcid.org/0000-0001-9873-6937 


\section{Christianne Luce Gomes}

Professora da Universidade Federal de Minas Gerais e docente permanente do Programa de Pós-graduação Interdisciplinar em Estudos do Lazer. Pesquisadora do CNPq PQ-Nível 2, Área do Turismo, e da FAPEMIGPPM. Doutora em Educação (UFMG, 2003), com Pós- doutorado em Ciências Políticas e Sociais (Univ. Nacional de Cuyo, 2012) e Estágio Sênior na Universidade de Barcelona (Bolsista CAPES 2017-2018). Líder do Grupo de Pesquisa LUCE - Ludicidade, Cultura e Educação. E-mail: chris@ufmg.br.

ORCID: http://orcid.org/0000-0002-0075-289X 